Review

\title{
Synthesis and Characterization of Graphene Flakes from Graphite by Using Biosurfactant - A Review
}

\author{
Praseetha Prabhakaran Kala , Fathima Mushrifa Anwar-Samath \\ Noorul Islam Centre for Higher Education, Thuckalay, Tamil Nadu, India. \\ Corresponding author. E-mail: crkpkp@gmail.com; Tel.: +91 9486855091
}

Received: Mar. 24, 2018; Accepted: Jul. 11, 2018; Published: Aug. 9, 2018.

Citation: Praseetha Prabhakaran Kala, Fathima Mushrifa Anwar-Samath, Synthesis and Characterization of Graphene Flakes from Graphite by Using Biosurfactant - A Review. Nano Biomed. Eng., 2018, I0(3): 235-242.

DOI: 10.5101/nbe.v10i3.p235-242.

\begin{abstract}
Exfoliation of graphene from graphite is one of the leading processes in the branch of nanotechnology, where surfactants are used as a unique solvent in combination with graphite and nitrogen gas atmosphere. This process would let the graphite to reduce into a monolayer in the presence of liquid phase with surfactants which have the equal surface energy to exfoliate graphene from graphite. There are many applications in nanotechnology for graphene flakes, but the production is costly as it is quite challenging to indulge graphite in the liquid phase. This review gives vast information about introducing a surfactant taken from various sources for exfoliating graphene flakes. It also provides a broad background regarding the isolation, production, and extraction of biosurfactants from organisms along with its role in nanotechnology.
\end{abstract}

Keywords: Graphite; Biosurfactant; Exfoliation; Graphene flakes

\section{Introduction}

The word nanotechnology implies a meaning which deals with nanoparticles $\left(10^{-9} \mathrm{~m}\right)$. This prefix nano was derived from the Greek word "nano" which means dwarf. The technology which is highly used upon nano substances for the enhancement of science is known as nanotechnology. At present, the synthesis of nanoparticles is given more importance as they possess lots of applications in the field of medical technology. The nanoparticles will possess a nanostructure with 1-100 nm dimensions [1, 2]. The use of nanoparticles is depended on their shape, size, dimension and composition [1]. These particles are prepared through physical, chemical and physiochemical process which is highly indulged in high pressure, temperature, energy, toxic biological compounds and so on [3]. In those aspects, this review deals with the synthesis of graphene flakes from graphite with the help of a biosurfactant

\section{Biosurfactants: A Natural Oil Degrading Compound}

Biosurfactants are surface-active compounds which reduce the interfacial tension between two liquids or between a liquid and a solid $[4,5,6]$. They profoundly indulge in bioremediation process $[7,8]$. These biosurfactants are found to have two main properties, and they are: Hydrophilic, water liking heads; and Hydrophobic, water-hating tails. 
Since they possess these two characters, they are found to be amphiphilic [9]. These biosurfactants can degrade oil in water [3]. This property is postulated to be its primary character $[10,11]$. Synthesis of biosurfactant is a significant setback in economy [12]. The production cost is based on the amount and type of raw materials that are contributed to the production. To reduce the cost of this material, the use of lowcostnatural materials is suitable for producing a significant amount of biosurfactants [13]. The output of nanographene flakes from biosurfactants is done at slower-rate approaches with reducing agents with reaction time between 24-120 $\mathrm{h}$ [14].

\section{Sources of Biosurfactant}

The biosurfactant compound is obtained from the cell wall of microorganisms, especially from bacteria upon which many researches have undergone [7-11, 15]. But there are some sources through which the production of biosurfactant is brought out in large quantities. For this purpose, the overall historical perspective of researchers has put forth four primary sources for biosurfactant production, and they are mentioned below: Plant source; Natural source - corn steep liquor, agro-based wastes; Animal source; and Direct usage of microorganism.

\section{Plant source mediated biosurfactant production}

According to the historical perspective of biosurfactant isolation, the survey and research have not produced any evidence for direct isolation of biosurfactants from plants. Instead, they have been used as a source for its production. The collaboration of microorganisms with plants is highly seen in the isolation process. Either the origin of the organism would have a connection with plants or the production of biosurfactants is done along with the support of plant source. According to the research, the biosurfactant isolated in a high amount from Lactobacillus paracas was from Portuguese diary plant. Keeping dairy plant as a primary source, the microorganism was found to produce biosurfactant with the decrease in the surface tension of $6.4 / \mathrm{mm}$ and $22.0 \mathrm{~m} / \mathrm{Nm}$, respectively [5]. Likewise, extracellular biosurfactant seemed to reduce the surface tension from 72.0 to $32.0 \mathrm{~m} / \mathrm{Nm}$. It was isolated from a new species namely Leucobacter yamagata; A bacteria dwelled in a mangrove sediment soil sample in the southern part of Thailand through an enrichment culture technique with lubrication oil as a carbon source [16].

Another research stated that the yeast strain (n $=160$ ) which produced biosurfactant was isolated from the various flowering plants such as bees Apis mellifera, etc.; the production of biosurfactant in this plant source was proved through oil spreading assay. The oleic acid in sunflower oil is used to increase the activity of biosurfactant strains. The methodology of producing and culturing of biosurfactant seemed to be similar to the production of biosurfactant directly from microorganisms without any interventions [17].

\section{Natural sources}

Natural sources are nothing but something which we get naturally without undergoing any preliminary processes. Here, we can find biosurfactants only at the cell wall of microorganisms. This was the known fact found from the entire investigation of biosurfactant production. But some of the natural sources are used as a starter to produce a significant amount of biosurfactant at low costs.

\section{Corn steep liquor}

The biosurfactants are extracted from corn steep liquor (CSL) [2] through spontaneous fermentation of lactic acid present in it (Scheme 1). The recent research upon CSL found that the lactic acid bacteria could produce some important concentrations of natural biosurfactants when it was allowed to grow in it (12.0 $\pm 0.5 \mathrm{~g} / \mathrm{Kg}$ of CSL); it would also prevent the growth of pathogenic microorganisms [13]. The filtration of these secondary metabolites helped to reduce the sizeable insoluble molecule and the extract could be obtained. This extract was further centrifuged to obtain the crude biosurfactant. Similarly, according to the research on Lactobacillus pentosus grown in CSL, and the following amount of biosurfactant was extracted [18].

Table 1 Biosurfactant production from corn steep liquor

\begin{tabular}{cccc}
\hline Dilutions & $\begin{array}{c}\text { Biosurfactant } \\
\text { extracted }(\mathrm{g})\end{array}$ & $\begin{array}{c}\text { Corn steep } \\
\text { iquor }(\mathrm{kg})\end{array}$ & Ref. \\
\hline Water & $12.3 \pm 1.8$ & 1 & {$[13]$} \\
Methanol & $11.5 \pm 0.7$ & 1 & {$[18]$} \\
LB medium & 1.3 & 1 & {$[13]$} \\
\hline
\end{tabular}

Note: LB = Lysogeny broth

\section{Agro-industrial waste}

The research on Bacillus subtilis stated that when 


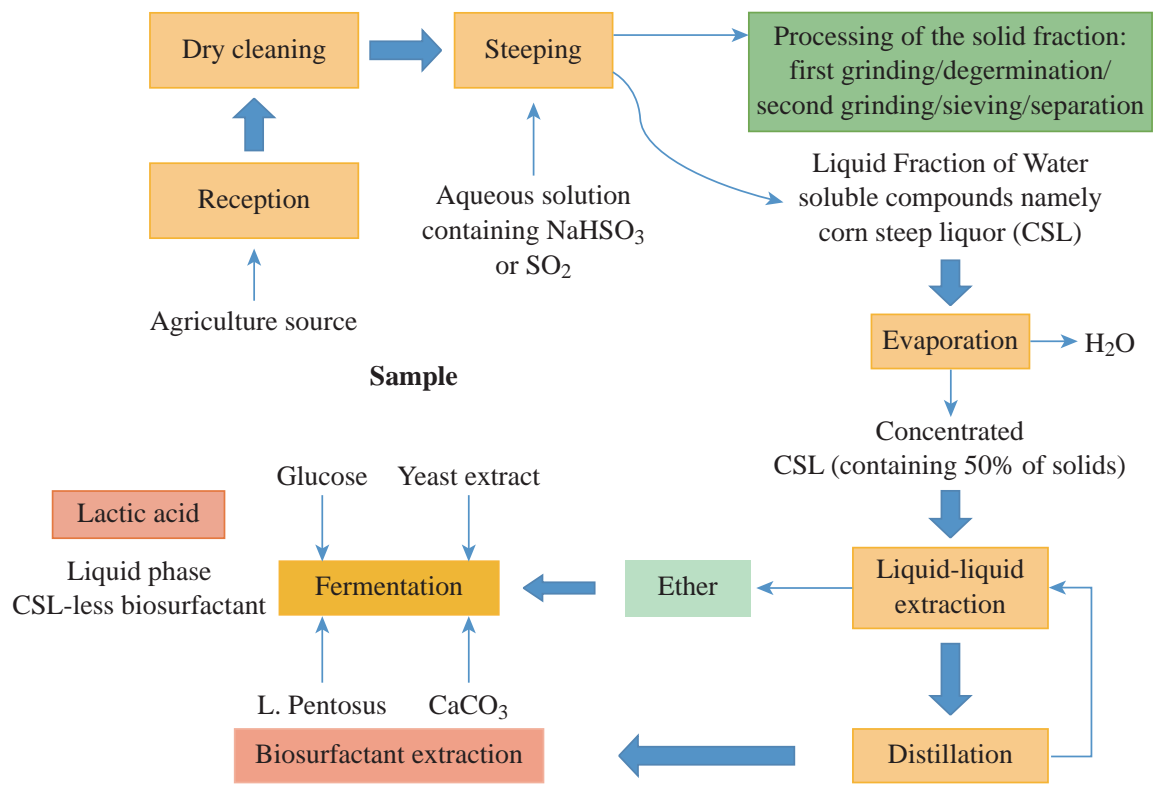

Scheme 1 A flowchart illustrating corn steep liquor production (CSL) and the extraction of biosurfactant [2, 22, 34, 35].

they were grown on different cheap carbon sources such as whey, molasses, and extract of potato peels, orange peels, banana peels, cooking oil, coffee wastewater and bagasse, more amount of biosurfactant were produced [19, 20].

Table 2 Biosurfactant production from Agro-industrial waste

\begin{tabular}{ccc}
\hline $\begin{array}{c}\text { Agro-industrial waste } \\
\text { (carbon sources) }\end{array}$ & $\begin{array}{c}\text { Biosurfactant } \\
\text { production }(\mathrm{g} / \mathrm{L})\end{array}$ & Ref. \\
\hline Bagasse extract & $0.127 \pm 0.002$ & {$[19]$} \\
Orange & $0.089 \pm 0.001$ & {$[19]$} \\
Whey & N/A & {$[19]$} \\
Waste cooking oil & 3.7 & {$[20]$} \\
Date molasses & 80 & {$[22]$} \\
\hline
\end{tabular}

\section{Biosurfactant isolated from animal skin}

The sample was collected from lingual area in the ear canals of adult dogs and cats, with the help of rolling wet swabs. After dipped into the separate Stuart transport media in a cool box, the swab was cultured in blood agar media. Several screening tests proved the presence of biosurfactant in the oily skin of dogs and cats [23]. Apart from that, it was reported that biosurfactants were also isolated from the oily skin of cows, sheep, goats, and the breast skin of turkeys, chickens, quails, etc. $[6,24]$. But this method is not highly used in the present scenario as the researchers have not much involved animals due to specific ethical issues [24]. Table 1 depicts the list of microorganisms producing biosurfactants isolated from sensitive areas of animals. Through the below-mentioned results, we can understand that in natural sources, the production of biosurfactant is becoming higher and cheaper, and so significant amount could be produced.

\section{Extraction of Biosurfactant from Microorganisms}

Microorganisms produce biosurfactants from the extracellular region of the organism [11]; biosurfactants are highly produced during their growth phase on water-immiscible substrates [21]. Amongst all, bacteria, yeast and fungi are the potential producers of biosurfactants [10]. These biosurfactants are determined based on their structure, location, size and their functional group [1]. Rosenberg and Ron classified biosurfactant into two main divisions, including: Low molecular weight surface active agents: Glycolipids, lipopeptides, phospholipids [25]; and High molecular weight polymers: Bioemulsifierpolymeric and particulate biosurfactants, which might be anionic or neutral.

Based on the growth condition and the type of microorganism, production of this secondary metabolite takes place. Most of the biosurfactants produced by microorganisms are isolated from contaminated soil, effluents and waste-water resources [25].

Five main types of biosurfactants are produced by a microorganism, and they are: Hydroxylase and cross-linked fatty acids; Glycolipids-rhamnolipids; 
Table 3 Biosurfactant production by various bacteria's isolated from the oily skin of dogs, poultry and cows

\begin{tabular}{|c|c|c|c|c|c|c|c|}
\hline \multirow{2}{*}{$\begin{array}{l}\text { Bacteria containing biosurfactants } \\
\text { Isolated Bacteria }\end{array}$} & \multicolumn{3}{|c|}{ Ears } & \multicolumn{3}{|c|}{$\mathrm{L} / \mathrm{A}$} & \multirow[t]{2}{*}{ Ref. } \\
\hline & E $24 \mathrm{~h}(\%)$ & E 72 h (\%) & O.S. SD (cm) & E 24 h (\%) & E 72 h (\%) & O.S. SD (cm) & \\
\hline \multicolumn{8}{|c|}{ Bacteria isolated from own dogs } \\
\hline Bacillus spp. & 52 & 52 & $4.65 \pm 0.07$ & 54.5 & 63.6 & $5.65 \pm 0.21$ & {$[6]$} \\
\hline Lactobacillus spp. & 54.5 & 59 & $6.7 \pm 0.28$ & 45.5 & 47.2 & $6.1 \pm 0.56$ & {$[6]$} \\
\hline Control & 50 & 50 & $4.7 \pm 0.14$ & 50 & 50 & $4.7 \pm 0.14$ & {$[6]$} \\
\hline \multicolumn{8}{|c|}{ Bacteria isolated from cows } \\
\hline Pasteurella spp. & 47 & 60 & $5.4 \pm 0.2$ & 52.3 & 47.8 & $4.5 \pm 0.3$ & [23] \\
\hline Acinetobacter spp. & 56.5 & 52.1 & $6.02 \pm 0.25$ & 59 & 58.3 & $5.4 \pm 0.1$ & [23] \\
\hline Control & 50 & 50 & $3.55 \pm 0.05$ & 50 & 50 & $3.55 \pm 0.05$ & [23] \\
\hline \multicolumn{8}{|c|}{ Bacteria isolated from poultry skin } \\
\hline Staphylococcus spp. & 44 & 44 & $5.05 \pm 0.35$ & 47 & 54.5 & $5.25 \pm 0.07$ & [24] \\
\hline Bacillus spp. & 44 & 51.9 & $5.2 \pm 0.34$ & -- & -- & -- & [24] \\
\hline Control & 40 & 40 & $4.4 \pm 0.1$ & 40 & 40 & $4.4 \pm 0.1$ & [24] \\
\hline
\end{tabular}

Note: E: Emulsification activity; SD: Standard deviation.

Table 4 List of some microorganisms producing biosurfactant

\begin{tabular}{|c|c|c|}
\hline Biosurfactant type & Microbial species & Ref. \\
\hline \multicolumn{3}{|c|}{ Glycolipids } \\
\hline Trehalose mycolates & Rhodococcus erythropolis & {$[1]$} \\
\hline Rhamnolipids & Pseudomonas aeruginosa & {$[26,27,28,29]$} \\
\hline Rhamnolipids & Vibrionaceae & {$[30]$} \\
\hline \multicolumn{3}{|c|}{ Phospholipids and fatty acids } \\
\hline Phospholipids; fatty acids & Candida sp.; Corynebacterium sp.; C. lepus & {$[21]$} \\
\hline \multicolumn{3}{|c|}{ Lipopeptides and lipoproteins } \\
\hline Fengycin & Bacillus thuringiensis CMB26 & {$[1]$} \\
\hline Peptide lipids & Bacillus licheniformis & {$[21]$} \\
\hline Surfactin; subtilysin; subsporin & Bacillus subtilis & {$[32,33]$} \\
\hline Surface active lipids & Rhodococcus erythropolis & {$[34]$} \\
\hline Probiotics & Bacillus spps. & {$[35]$} \\
\hline \multicolumn{3}{|c|}{ Polymeric biosurfactants } \\
\hline Emulsan & Acetobacter calcoaceticus & {$[21]$} \\
\hline \multicolumn{3}{|c|}{ Particulate biosurfactants } \\
\hline Fimbriae; whole cell & Acinetobacter calcoaceticus; Cyanobacteria & [35] \\
\hline
\end{tabular}

Lipopolysaccharides; Lipoproteins-Lipopeptides; and Fatty acids, phospholipids and neutral lipids.

\section{Exfoliation of Graphene Flakes from Graphite \\ Graphite}

Graphite is carbon filled with thin, fragile crystals which are more sensitive to be handled. They are silver-grey to black and are brittle in texture. It has a greasy feel which smudges the hands when touched. These non-metallic elements are good conductors of electricity and bad conductor of heat. Graphite is an igneous, metamorphic rock which is not used for its original size. The sliced graphites are moulded as sharp tips. The scientists at University of Cambridge 
used three-step polishing method to produce graphite tips less than $5 \mu \mathrm{m}$ and shaped to sub-100 $\mathrm{nm}$ in size, and of particular geometries [36]; these tips possess several nanotechnological applications such as: Tomographic holders; Probes for micromanipulation; Semiconducting probes for electrical measurements; and Probes in organic systems to study their elastic properties.

\section{Graphene exfoliation}

Graphene is nothing but the sliced part of graphite. It is very challenging to produce graphene which is an allotrope of carbon, e.g., graphite, diamonds, etc. It is a hexagonal lattice forming a single layer of carbon atoms. It consists of a single atomic lattice of hexagonally arranged sp2 hybridised carbon atoms [37]. It was invented after the introduction of nanocarbon tubes. These nanocarbon tubes are highly required in the market, which are produced by rolling up several graphene sheets to form a concentric hollow structure. These containers can function as a conductor or a semiconductor based on the rolled shape and the diameter of the tubes. This invention leads to the shedding of graphene sheets that are collectively known as NGPs, which is an abbreviation for nano-scaled graphene platelets. The application of graphene flakes in the area of carbon materials exposed a successful cleavage of graphene material through micromechanical cleavage or chemical exfoliation of highly oriented pyrolytic graphite or graphite oxide [42]. Graphene can be collected from bulk solution with the use of solvents in oil or water, as it tightens the graphene films by reducing the concentration of solution and results in graphene films [38, 43].

\section{Surfactant-mediated exfoliation of graphene flakes}

The production of graphene flakes from graphite through exfoliation is an ongoing exciting process in the field of nanotechnology. This peeling is highly depended upon a surfactant, a compound which is used to reduce the interfacial tension between two liquidliquid or liquid-solid media [4]. Several procedures were put forth by many scientists to extract graphene flakes from graphite. A primaryway of exfoliating a graphene flake from graphite with the help of a surfactant is given as below: Sonicated graphite powder added to $\rightarrow$ Surfactant solution mixed with glacial acetic acid and introducing to a nitrogen atmosphere $\rightarrow$ Centrifugation and suspension of black residue in dimethylformamide (DMF).

Apart from this basic method, there are some other methods of isolation, such as through tip sonic synthesis using sodium cholate as a surfactant in the presence of Millipore water as a medium, through anionic charge molecule such as Gemini-type peptide IleIleIleCys-CysIleIleIle which sticks towards the surface of graphite and involves the exfoliation process. It has higher efficiency in determining the exfoliating capacity of graphite. A surfactant is an effective component to exfoliate graphene from its solution [37, 39]. When we peepep into the commercialisation of graphene in the market, we found the content of the product was needed in large amount. For that purpose, mass production of graphene flakes is in demand. In those aspects, liquid phase exfoliation through any surfactant is highly achieved to obtain more amount of sample [40].

Finally, the end product graphene flakes are obtained and are further characterised through several studies like scanning electron microscope (SEM), transmission electron microscope (TEM), Fourier transform infrared spectroscopy (FTIR), Raman spectroscopy, ultravioletvisible spectroscopy (UV-Vis) etc. [14].

\section{Biosurfactant mediated graphene synthesis}

Till date, there has been no published research done

Table 5 List of graphene synthesisedby several surfactants

\begin{tabular}{|c|c|c|c|c|}
\hline SL. No & Surfactant used & Exfoliated compound & Method & Ref. \\
\hline 1 & Sodium Cholate & Graphene flakes & Tip sonication \& centrifugation & 37 \\
\hline 2 & Cyclo hexane & Graphene film & Micromechanical cleavage & 38 \\
\hline 3 & $\begin{array}{c}\text { Anionic molecule } \\
\text { (Gemini-type peptide IleIleIleCys-CysIleIleIle) }\end{array}$ & Graphene Sheets & Sonication & 39 \\
\hline 4 & Ortho-dichlorobenzene (solvent) & Graphene film & Liquid phase exfoliation & 40 \\
\hline 5 & -- & Graphite flakes & VWR ultrasonic cleaner \&, centrifugation & 41 \\
\hline
\end{tabular}


regarding the production of graphene with the help of a biosurfactant. The biosurfactant is a compound obtained from the cell wall of microorganisms, especially bacteria are highly economical when compared to the other sources $[45,46]$. In biosurfactant mediated exfoliation, surfactant extracted from microbes such as Bacillus subtilis, Pseudomonas aeruginosa etc. can be used as a solvent which makes the water as an exfoliating medium and withstand the property of the graphene [44].

\section{Characterization of the product}

Characterization determines the presence of graphene flakes in the sample containing biosurfactant and co-products. It will act as a confirmatory part in the production of graphene flakes from graphite along with a microbial biosurfactant.

FTIR: The sample goes through this technique to reveal the functional group and chemical nature of the extracted compound [7].

Atomic force microscopy (AFM): The sample is characterised in AFM to show some of its properties, such as high friction magnetism, etc. For this purpose, the dilute solution of graphene is spin coated on freshly cleaved mica at a speed of $5000 \mathrm{rpm}$ and dried at room temperature [15].

SEM: With EDAX, SEM is done to differentiate the particle and the residual surfactant [28].

Raman spectrometer: Raman spectra are the most conformational characterisation technique which confirms the presence of graphene flakes in the sample. It is operated at an excitation wavelength of $532 \mathrm{~nm}$ [32].

TEM: This is one of the most powerfulcharacterisation techniques. Through SEM characterisation, the thin layers of graphene flakes, films or sheets can be seen as they are dispersed onto a holey carbon mesh grid of the instrument, and the result is produced through several treatments such as solvothermal treatment based on the sample provided onto it [41].

Here, Raman spectroscopy is said to be as the most important and confirmatory characterization method for graphene. In Raman spectroscopy, the formation of $D, G$ and 2D bands with their respective wavelength, such as 1580 and $2700 \mathrm{~nm}$ of $\mathrm{G}$ and 2D band, indicates the confirmed presence of graphene $[45,46]$.

\section{Effects of surfactant in exfoliating graphene}

Surfactants play a vital role in exfoliating graphene by reducing the high surface energy $\left(72.8 \mathrm{~mJ} / \mathrm{m}^{2}\right)$ of water, making it act as a medium and optimizing the interaction of graphite surface to reduce its structure into a graphite [49]. This surfactant has the capacity to withstand the material property of a graphene. But chemical surfactant can change the material property due to some chemical reactions. Instead, a microbial surfactant can hold on the graphene property as such and can further undergo characterizations [50].

\section{Conclusions}

Through this review, a clear background of biosurfactant isolation, its production and how it is bridged up with nanotechnology is seen. The graphene flake production is stressed here because of its importance in the current scenario; graphene flakes are used for many purposes as listed below:

They are extensively used in the field of electricity, conductivity, energy generation, batteries, sensors, carbon nanotubes, etc. [38].

The first and the leading producer of graphene was produced by Siren Technology Security Smart Packaging Company where graphene-based ink was produced in Vorbeck Materials. They are used to fabricate macroscopic materials with different compositions and nanostructures. Nanomedical graphene-based sensors were invented in December 2016, San Diego-based Nanomedical Diagnostics. These sensors have higher accuracy and portability, and are cost-saving [39].

Graphene tennis rackets and graphene thermal paste were produced by HEAD and Thermene in 2013, as well as graphene-enhanced skis for women as they would be lightweight and durable. Apart from that, the exfoliation process acts as a model for exfoliation mechanism for innovative design of LPE schemes [40, 51].

\section{Conflict of Interests}

The authors declare that no competing interest exists.

\section{References}

[1] A.P. Grazyna, C. Joanna, M.B. Ibrahim, et al., 
Biosurfactant Mediated Biosynthesis of Selected Metallic Nanoparticles. International Journal of Molecular Science, 2014, 15: 13720-13737.

[2] B.B. Charles, A.B. Farias, F.S. Aline, et al., Synthesis of silver nanoparticles using a biosurfactant produced in low-cost medium as stabilising agent. Electronic Journal of Biotechnology, 2014, 17: 122-125.

[3] S.M.I. Morsy, Role of surfactants in nanotechnology and their applications. International Journal of Current Microbiological Applications Science, 2014, 3(5): 237260.

[4] M. Fathima, S. Poornima, Isolation and characterization of biosurfactant - producing marine bacteria, isolated from the Chinna Muttam fishing harbor, Kanyakumari District. Research Journal of Pharmaceutical, Biological and Chemical Sciences, 2017, 8(5): 249.

[5] E.J. Gudiña, V. Rocha, J.A. Teixeira, et al., Antimicrobial and antiadhesive properties of a biosurfactant isolated from Lactobacillus paracasei ssp. paracasei A20. Letters in Applied Microbiology, 2010, 50 (4): 419-424.

[6] E. Azizollah, T. Najmeh, and L. Sharareh, Isolation of biosurfactant producing bacteria from oily skin areas of small animals. Jundishapur Journal of Microbiolog, 2012, 5(2): 401-404.

[7] T.H. Swapna,, N.K. Papathoti, M.Y. Khan, et al., Bioreduction of $\mathrm{Cr}$ (VI) by biosurfactant producing marine bacterium Bacillus subtilis SHB 13. Journal of Science and Industrial Res., 2016, 75: 432-438.

[8] D. Seema, D.J. Nakuleshwar, Isolation of biosurfactant producing marine bacteria. African Journalof Environmental Science and Technology, 2012, 6(6): 263266.

[9] S. Pooja, R. Selvan, K.S. Jitendra, et al., Production of biosurfactant stabilized nanoparticles. International Journal of Pharma and Bio Sciences, 2017, 8(2): (B) 701707.

[10] N. Rehman, M. Aziz, M. Shete, et al., Screening of biosurfactant producing microorganisms from oilcontaminated soils of Osmanabad region, Maharashtra Indian. International Social Science Journal, 2014, 1: 3539.

[11] R. Thavasi, S. Jayalakshmi, and M. Banat, Biosurfactants from marine bacterial isolates. Current Research, Technology and Education Topics in Applied Microbiology and Microbial Biotechnology, 2010: 1367-1371.

[12] G.S. Kiran, A. Sabu, and S. Joseph, Synthesis of silver nanoparticles by glycolipid biosurfactant produced from marine Brevibacterium casei MSA19. J Biotechnol., 2010, 148: 221-225.

[13] X. Vecino, P. Barbosa, R. Devesa, et al., Optimization of liquid-liquid extraction of biosurfactants from corn steep liquor. Bioprocess and Biosystems Engineering, 2015, 87: 427-464.

[14] K. Umar, N. Arlene, P. Harshit, et al., Size selection of dispersed, exfoliated graphene flakes by controlled centrifugation. Carbon, 2012, 50: 470-475.

[15] V. Sajini, P. Jinu, and V. Suresh, Cationic surfactant mediated exfoliation of graphite into graphene flakes. Carbon, 2009, 47(14): 3288-3294.

[16] S. Kanokrat, M. Suppasil, and S. Atipan, Isolation and characterization of biosurfactants-producing bacteria isolated from palm oil industry and evaluation for biosurfactants production using low-cost substrates. Journal of Biotech, Computational Biology and Bionanotech, 2013, 94(3): 275-284.

[17] O.D. Lanieva, Biosurfactant-producing yeasts isolated from flowering plants and bees. Mikrobiolohichny̌ zhurnal, 2013, 75(4): 53-59.

[18] G.G. Sergio, P.A. María, V. Xanel, et al., Biogenic synthesis of metal nanoparticles using a biosurfactant extracted from corn and their antimicrobial properties. Nanomaterials, 2017, 7: 139.

[19] N.R. Ashwini, V.B. Vishakha, V. Ravi Kumar, et al., Agro-industrial wastes for production of biosurfactant by Bacillus subtilis ANR 88 and its application in synthesis of silver and gold nanoparticles. Frontiers in Microbiol, 2017, 8: 492.

[20] Y.O. Gustavo, S.C. Gilberto, B.G. Cristina, et al., Utilization of agro industrial waste for biosurfactant production by native bacteria from Chiapas. Open Agriculture, 2017, 2: 341-349.

[21] D.D. Jitendra, M.B. Ibrahim, Microbial production of surfactants and their commercial potential. Microbiology and Molecular Biology Reviews, 1997, 61(1): 47-64.

[22] S.N. Al-Bahry, Y.M. Al-Wahaibi, and A.E. Elshafie, Biosurfactant production by Bacillus subtilis B20 using date molasses and its possible application in enhanced oil recovery. International Biodeterioration Biodegradation, 2012, 81: 141-146.

[23] E. Azozillah, T. Najmeh, and K. Saeid, Biosurfactant Producing Bacteria on Oily Areas of Ruminant Skin. Spring, 2011, 7(2): 117-121.

[24] E. Azizollah, T. Najmeh, and R.S. Rashmi, Isolation of biosurfactant-producing Pseudomonas aeruginosa RS29 from oil-contaminated soil and evaluation of different nitrogen sources in biosurfactant production. Annals of Microbiology, 2012, 62: 753-763.

[25] Breast Skin, Jundishapur Jundishapur Journal of Natural Pharmaceutical Products 7(3): 93-96.

[26] D. Jolien, D.M. Katrien, P. Ellen, et al., Biosurfactants in plant - Pseudomonas interactions and their importance to biocontrol. Environmental Microbiology Reports, 2010, 2(3): 359-372.

[27] W. Panisara, P. Orathai, T. Tuspon, et al., Synthesis of polyaniline nanofibers and nanotubes via rhamnolipids biosurfactant templating. Synthetic Metals, 2011, 161: 298-306.

[28] H.E. Reiling, T.E. Thanei, L.H. Guerra, et al., Pilot plant production of rhamnolipid biosurfactant by Pseudomonas aeruginosa. Applied And Environmental Microbiology, 1986, 51(5): 985-989.

[29] P. Prakash, M.R. Ashok, Synthesis of spherical NiO nanoparticles through a novel biosurfactant mediated emulsion technique. Materials Science and Engineering: C, 29(1): 199-204

[30] P. Anders, M. Goran, Capacity for biosurfactant production of environmental Pseudomonas and Vibrionaceae growing on carbohydrates. Applied Microbiology and Biotechnology, 1987, 26: 439-442.

[31] V. Thivaharan, R.M. Vytla, Production of a Lipopeptide Biosurfactant by a Novel Bacillus sp. and Its Applicability to Enhanced Oil Recovery.ISRN Microbiology, 2013, 7382.

[32] A.S. Reddy, C.Y. Chen, S.C. Baker, et al., Synthesis of silver nanoparticles using surfactin: A biosurfactant as stabilizing agent. Materials Letters, 2009, 63: 1227-1230.

[33] P. Das, S. Mukherjee, and R. Sen, Antimicrobial potential of a lipopeptide biosurfactant derived from a marine Bacillus circulans. Journal of Applied Microbiology, 2008, 104(6): 1675-1684.

[34] A. Khopade, R. Biao, X. Liu, et al., Production and stability studies of the biosurfactant isolated from marine Nocardiopsis sp. B4. Desalination, 2012, 285: 198-204.

[35] E.J. Gudiña, V. Rocha, J.A. Teixeira, et al., Isolation and functional characterization of a biosurfactant produced by Lactobacillus paracasei. Colloids and Surfaces B, 2010, 76(1): 298-304.

[36] D. Sanz-Hernández, R.F. Hamans, J.W. Liao, et al., Fabrication, detection, and operation of a threedimensional nanomagnetic conduit. ACS Nano, 2017, 
11(11): 11066-11073.

[37] N. Khalid, A. Muhammad, M.B. Khan, et al., Effect of Concentration of surfactant on the exfoliation of graphite to graphene in aqueous media. Nanomater Nanotechnol, 2016, 6: 14.

[38] Z. Tang, J. Zhuang, and X. Wang, Exfoliation of Graphene from Graphite and Their Self-Assembly at the Oil-Water Interface. Langmuir, 2016, 26(11): 9045-9049.

[39] M. Cao, N. Wang, L. Wang, et al., Direct exfoliation of graphite into graphene in aqueous solutions of amphiphilic peptides. Journal of Materials Chemistry B, 2016, 4: 152

[40] N. Rekha, O.K. Sang, Surfactant mediated liquid phase exfoliation of graphene. Springer Open Journal, 2015, 2: 20.

[41] K.B. Ricardo, A. Sendecki, and H. Liu, Surfactantfree exfoliation of graphite in aqueous solutions. Electronic Supplementary Material (ESI) for Chemical Communications, 2014, 21.

[42] I.K. Snook. A.S. Barnard, Theory, experiment and applications of graphene nano-Flakes. J. Nanosci. Letters, 2011, 1(1): 50-60.

[43] B. Somnath, B. Kumar, A review on the properties and applications of graphene. J. Material. Sci. Mech. Engg., 2016, 2(10): 70-73.

[44] B.S. Saharan, R.K. Sahu, and D. Sharma, A review on biosurfactant, fermentation, current developments and production. Gen. Eng. Biotechnol. J., 2011: 10-14.

[45] R. Marchant, I.M. Banat, Biosurfactants: A sustainable replacement for chemical surfactants. Biotechnol. Let., 2012, 34: 1597-1605.

[46] E.C. Souza, T.C. Vessoni-Penna, and R.P. Souza Oliveira, Biosurfactant-enhanced hydrocarbon bioremediation: An overview. Int. Biodeterior. Biodegrad., 2014, 89: 88-94.

[47] F. Tuinstra, J.L. Koenig, Raman spectrum of graphite. The Journal of Chemical Physics, 1970, 53: 1126.

[48] J. Sathyanarayan, J. Kunthala, and K. Gurumurthy, Optimization of MRS media components using response surface methodology for the riboflavin production by Lactobacillus fermentium isolated from yoghurt sample. Int. Food. Res. J., 2011, 18: 149-158.

[49] M. Lotya, Y. Hernandez, P.J. King, et al., Liquid phase production of graphene by exfoliation of graphite in surfactant or water solutions. J. Am. Chem. Soc., 2009, 131: 3611-3620.

[50] K.F. Danyelle, S.R. Rufino, and A. Sarubbo, Biosurfactants: Multifunctional biomolecules of the 21st century. Int. J. Mol. Sci., 2016, 17(3): 401.

[51] U. Khan, P May, A. O'Neill, et al., High- concentration solvent exfoliation of graphene. Carbon, 2010, 48: 40354041.

Copyright $\subset$ Praseetha Prabhakaran Kala, Fathima Mushrifa Anwar-Samath. This is an open-access article distributed under the terms of the Creative Commons Attribution License, which permits unrestricted use, distribution, and reproduction in any medium, provided the original author and source are credited. 